\title{
Improving the Adoption of Advance Directives in Primary Care Practices
}

\author{
Elizabeth Wickersham, MD, MS, Mary Gowin, MPH, PhD, Munim H. Deen, MPH, CPH, \\ and Zsolt Nagykaldi, $P h D$
}

Background: Oklahoma's Advance Directive completion rate is less than $10 \%$. We compared the implementation performance of 2 advance directive forms to determine which form could be more successfully disseminated.

Methods: The implementation of the Oklahoma Advance Directive (OKAD) and the Five Wishes form were compared in an 8-month pair-matched cluster randomized study in 6 primary care practices. The outcomes measured during the 22-week implementation included form offering rate, acceptance/completion rate by patients, and documentation in the chart. Twenty semistructured interviews with patients and clinicians were conducted to assess intervention experience.

Results: A total of 2748 patient encounters were evaluated. OKAD was offered in $33 \%$ of eligible patient visits (493/1494) and accepted 54\% of the time (266/493). Five Wishes was offered in $36 \%$ of eligible patient visits (450/1254) and accepted $82 \%$ of the time $(369 / 450)$. Unadjusted analyses found no significant difference in offering of advance directive forms between groups. However, the odds of accepting Five Wishes were 3.89 times that of OKAD (95\% CI, 2.88 to $5.24 ; P<.0001)$. Logistic regression models controlling for several confounders indicated that the acceptance of Five Wishes was favored significantly over $\mathrm{OKAD}(\mathrm{OR}=1.52 ; 95 \% \mathrm{CI}, 1.27$ to $1.81 ; P<.0001)$. Qualitative analyses indicated a clear clinician and patient preference for Five Wishes.

Conclusions: Results suggest that Five Wishes was more readable, understandable, appealing, and usable. It seemed to capture patient preferences for end-of-life care more effectively and it more readily facilitated patient-clinician conversations. (J Am Board Fam Med 2019;32:168-179.)

Keywords: Advance Directives, End of Life Care, Living Wills, Oklahoma, Patient Preference, Patient-Centered Care, Primary Health Care, Quality of Life

In 2014, the Institute of Medicine (IOM) issued a report about the current state of medical care for persons with serious/terminal illnesses in the United States. ${ }^{1}$ The resulting report noted that the process of dying in the United States has dramatically changed as a result of fragmentation of med-

This article was externally peer reviewed.

Submitted 13 August 2018; revised 30 November 2018; accepted 4 December 2018.

From the Department of Family and Preventive Medicine, Research Division (EW, MG, ZN), Primary Care Health Policy Division (MG), Department of Biostatistics and Epidemiology, College of Public Health (MHD), University of Oklahoma College of Medicine, Oklahoma City, OK.

Funding: Funding for this project provided by National Institutes of Health grant U5GM104938 distributed through the Oklahoma Shared Clinical and Translational Resources (OSCTR) Grant C1092004 with matching funding from the Stephenson Cancer Center. Partial support ical care and barriers to access. In addition to these challenges, people are living longer and are frailer overall. This report identified several opportunities to improve on these issues including increasing clinician-patient communication and advance care planning (ACP).

An important part of ACP is the completion of an Advance Directive (AD). ADs specifically ad-

provided by National Institutes of Health, National Institute of General Medical Sciences (Grant 1 U54GM104938, PI

James) and National Institute on Minority Health and

Health Disparities (Grant 1R25MD011564, PI Stoner/

Houchen).

Conflict of interest: none declared.

Corresponding author: Elizabeth Wickersham, MD, MS, Research Division, Department of Family and Preventive Medicine, University of Oklahoma College of Medicine, 900 NE 10th St, Oklahoma City, OK 73104 (E-mail: elizabeth-wickersham@ouhsc.edu). 
Table 1. Characteristics of Pair-Matched Practices, Based on Clinician Survey Responses

\begin{tabular}{llcccccc}
\hline $\begin{array}{l}\text { Pair } \\
\text { Match }\end{array}$ & \multicolumn{1}{c}{ Practice Type } & $\begin{array}{c}\text { 2013 Locale } \\
\text { Population }\end{array}$ & Panel Size & Pts/Day & \% Medicare & $\begin{array}{c}\text { Reg Use of } \\
\text { AD Form }\end{array}$ & $\begin{array}{c}\text { \% Discuss } \\
\text { AD }\end{array}$ \\
\hline 1 & FQHC & 17,140 & $>2000$ & 12 & 25 to 49 & $\mathrm{~N}$ & 0 \\
1 & Independent & 6,027 & $>3000$ & $>40$ & 50 to 74 & $\mathrm{~N}$ & 1 to 24 \\
2 & Residency/Corporate & 610,613 & $>3000$ & 30 to 39 & 25 to 49 & $\mathrm{~N} \times 2, \mathrm{Y} \times 1$ & 1 to 24 \\
2 & Residency & 610,613 & $>3000$ & 40 & 25 to 74 & $\mathrm{Y} \times 1, \mathrm{~N} \times 4$ & 1 to 24 \\
3 & Independent & 23,400 & $>3000$ & 10 to 19 & 25 to 49 & $\mathrm{~N}$ & 0 \\
3 & Independent & 17,140 & $>3000$ & 20 to 29 & 50 to 74 & $\mathrm{~N}$ & 1 to 24 \\
\hline
\end{tabular}

2013 Locale Population, based on 2013 data; \% Discuss AD: Estimated percent of patients with whom the clinician believes they discuss ADs at baseline; FQHC, Federally Qualified Health Center; pts/day, estimated average number of patients seen per day; \% Medicare, estimated percent Medicare-insured patients; Reg Use of AD Form, Does the clinician use an AD form on a regular basis? ( $Y$, yes; $\mathrm{N}$, no, $\mathrm{X} \#$ indicates how many clinicians gave this answer).

$\mathrm{AD}$, Advance Directive.

dress one's ability to legally express one's desires regarding end-of-life (EOL) care. ${ }^{2}$ In Oklahoma, $\mathrm{ADs}$ are frequently unutilized until the patient's terminal care period, if then. Pilot data from our medical center inpatient palliative care consult team indicate an $\mathrm{AD}$ completion rate of $5 \%$ to $12 \% .^{3}$ A recent informal survey of the Oklahoma Physicians Resource/Research Network (OKPRN) members indicated $\mathrm{AD}$ completion rates between $0 \%$ to $12 \%$, averaging $5 \%$ to $7 \%$ in primary care. ${ }^{4}$ These completion rates clearly demonstrate the need for improved AD implementation strategies.

ACP conversations occur infrequently and if they occur, they generally take place when someone is gravely ill. This adds to the burden on the individual and family, decreasing the likelihood of decisions that are best aligned with the individual's goals for EOL care. As a result, many people die in a medical setting such as an intensive care unit. In contrast, most people report that ideally, their death would occur at home, surrounded by friends and family, free of pain. ${ }^{5}$ Without a completed $\mathrm{AD}$ there is a high probability that a person will die in the hospital, particularly the intensive care unit. ${ }^{2}$ In previous studies, the lack of user-friendly features has been identified as a barrier to successful $\mathrm{AD}$ adoption ${ }^{6}$ and given the fact that over a third of US adults have low health literacy, there is room for improvement in strategies for better AD implementation. ${ }^{7}$

Feedback from practitioners and our preliminary research indicate that a widely used alternative, the Five Wishes document, ${ }^{8}$ may be more useful and appropriate for most patients than the current Oklahoma Advance Directive for Health Care (OKAD) form. ${ }^{9}$ The OKAD is a 4-page document written at a 15.5 -grade reading level. There is a 20-page explanatory booklet available to assist with understanding for potential completers. It is available in 3 languages, containing highly technical and legal language and using complicated and sometimes poorly-defined medical terminology. In contrast, Five Wishes has an eighth-grade reading level, ${ }^{9}$ has been translated into 28 languages, and is legally accepted in 42 states, including Oklahoma. There are various options for people (web instructions, videos) to assist people with understanding the options presented by the form. The implementation and clinical performance of Five Wishes has not yet been compared with any state-sponsored form. This is particularly important when we consider that the average readability level of state-sponsored $\mathrm{AD}$ forms is grade 11.9, whereas the average reading level of adults in Oklahoma is far below this. ${ }^{7}$

This article describes a pilot study comparing the uptake of OKAD to that of Five Wishes. Our goal is to identify which form would be more acceptable to Oklahomans and to discover factors that influence $\mathrm{AD}$ implementation in general. This information will be used to develop a future larger randomized controlled trial to improve the implementation and dissemination of ADs in Oklahoma.

\section{Methods}

Six primary care practices were recruited via the OKPRN listserv $(\mathrm{n}=246)$, enrolled, and pairmatched based on practice size, type, patient mix, and geographical location to minimize differences in known covariates based on methodological standards for cluster-randomized trials. ${ }^{10}$ Practices were randomly allocated to the 2 study groups (1:1 OKAD vs Five Wishes; see Table 1). The study 
Figure 1. Workflow process for the distribution of advance directives in the clinics.

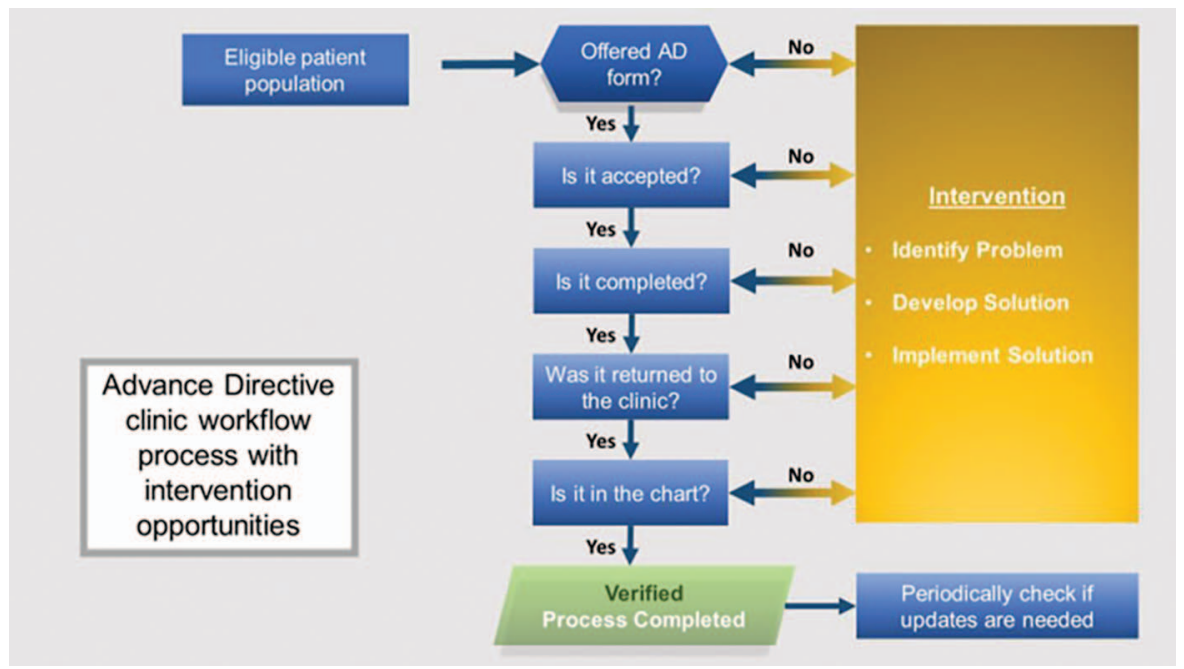

took place over a 22-week period from January 2017 through May 2017. Participants were blinded to the 2-arm assignment to minimize allocation awareness bias.

Patients 65 years or older with decision-making capacity presenting for nonemergent office visits were eligible for the study and those who accepted a form were considered patient participants. Retrospective chart abstractions examined a 5-year baseline period in a representative, randomly selected sample of medical records from these participants $(\mathrm{n}=100)$. This list was weighted based on the number of patient participants in each practice. Progress notes, reports, and attachments were examined to establish the existence of an $\mathrm{AD}$ completed within a 5-year time window. The date and the type of $\mathrm{AD}$ (if available) were recorded, along with the age and gender for each patient participant. This subset of 100 charts were reviewed at the end of the study for the number and type of active chronic conditions of patients to calculate a Charlson Comorbidity Index (CCI). ${ }^{11}$

Sample size estimates indicated that 60 patients in 6 practice clusters $(n=360)$, based on an interclass correlation coefficient of $0.02^{12,13}$ would provide sufficient power (80\%) to detect realistic and clinically meaningful differences in $\mathrm{AD}$ adoption rates between the 2 study groups (13\% to $17 \%$ ).

Each participating clinic was instructed to offer their assigned AD form to eligible patients in Spanish, English, or Vietnamese. We asked the clinician's medical staff to introduce the $\mathrm{AD}$ form as they were rooming the patient using a standardized 30 -second script, available in all 3 languages. To track the offering and acceptance of the AD forms, medical staff were also asked to keep a $\log$ tailored to fit the preferred workflow for each clinic. Two unique identifiers were recorded for each patient as well as information pertaining to 1) offering the $\mathrm{AD}$ (or why it was not offered); 2) acceptance of the $\mathrm{AD}$ (or why it was not accepted); and 3) comments for each patient, as appropriate. Logs were collected regularly by a practice facilitator $(\mathrm{PF})$ and compared with the daily schedule to identify a daily list of the proportion of eligible patients captured on the $\log$. Practice level participation data were recorded in a Microsoft SharePoint database, Redmond, WA and reviewed by the research team on a weekly basis. Individual-level outcomes were recorded in a REDCap database, Nashville, TN. ${ }^{14}$ $\mathrm{PFs}$ worked with practices to ensure sufficient implementation without deliberately maximizing implementation rates. As necessary, they helped the practices investigate strategies to improve the rate of offering the $\mathrm{AD}$ forms. At weekly meetings, the team discussed the challenges each practice faced as well as strategies they used to ensure sufficient implementation in each practice. We documented particularly helpful, high-performing processes for improving implementation for use in a subsequent "best practices" study. We illustrate the details of the workflow process in Figure 1.

To ensure the accuracy of the denominator, we compared documented patient schedules tracked 
by the practices to the numbers derived from the 2 databases. We compared proportions of $\mathrm{AD}$ offering and acceptance rates between OKAD and Five Wishes groups using $\chi^{2}$ statistics and performed subsequent analyses using logistic regression to model offering and acceptance of $\mathrm{AD}$ forms across study groups, controlling for patient age, gender, and CCI. A logistic regression model was fit to compare the odds of acceptance between the OKAD and Five Wishes arms. Generalized estimating equations (GEEs), with adjustment for the small number of practices in the study, were used to account for the impact of practice-level clustering. ${ }^{15,16}$ Quantitative data analyses were performed using SAS v9.4 (SAS Institute Inc., Cary, NC).

Qualitative analyses of individual semistructured interviews with participating clinicians and patients were conducted using a directive content analysis method. ${ }^{17}$ The same subset of 100 charts for the retrospective chart analysis and the CCI calculation served as the preliminary invitee list for the interviews. Patients were eliminated from the list if they did not speak English, did not return our calls after 3 attempts, or reported no recall of the $\mathrm{AD}$ form. The remaining patients were asked to participate in 30-minute telephone interviews conducted between 2 weeks and 4 months after the intervention visit to ensure reasonable recall. The patients who agreed to participate in phone interviews were verbally consented before the start of the interview and then consented in writing via a mailed consent form along with the gift card paperwork after the interview, while the clinician participants provided written consent before starting the interview. The interviews were digitally recorded, transcribed, then coded using NVivo v11 software (QSR International, Burlington, MA) by 2 independent researchers with qualitative analysis experience (EW and MG). Interviews were analyzed and coded iteratively based on a preliminary coding scheme developed previously with areas of disagreement argued to consensus. Our qualitative inquiry was intended to clarify the facilitators and barriers of specific $\mathrm{AD}$ implementation and thus, our overarching themes were anticipated by our interview guide. However, we were intentionally open to the emergence of unanticipated findings as well. $\mathrm{Pa}$ tients received a $\$ 35$ gift card for participation. Clinicians were interviewed at the end of the data collection period and participating practices received a $\$ 1000$ remuneration. Results were trian-
Table 2. Participating Patient Demographics

\begin{tabular}{llrc}
\hline \multirow{2}{*}{ Category } & \multicolumn{1}{c}{ Characteristic } & Count & $\begin{array}{c}\text { Percentage, } \\
\%\end{array}$ \\
\hline \multirow{2}{*}{ Gender } & Male & 232 & 35 \\
& Female & 440 & 65 \\
\multirow{4}{*}{ Race/ethnicity } & White & 337 & 73 \\
& Black & 54 & 12 \\
& Hispanic/Latino & 31 & 7 \\
& Native American/Alaskan & 7 & 2 \\
& Asian/Pacific Islander & 32 & 7 \\
\hline
\end{tabular}

Count is limited to the number of patient participants for whom this information was recorded by the clinical staff.

gulated to meaningfully supplement the quantitative analyses with patient and clinician feedback and practice-based observations from PF field notes.

\section{Results}

\section{Quantitative Outcomes}

Practice and patient participant characteristics are described in Tables 1 and 2, respectively. The median age of patients was 76 years (Figure 2).

Across 6 practices, 2748 patient encounters were eligible for inclusion in the study during a 22 -week implementation period. Of all eligible encounters, $\mathrm{AD}$ forms were offered to $34 \%$ of patients $(\mathrm{n}=$ $943)$ and accepted $67 \%$ of the time when offered $(\mathrm{n}=635)$.

OKAD was offered in $33 \%$ of eligible visits (493/1494), while Five Wishes was offered in 36\% of eligible visits (450/1254). The acceptance rate of OKAD was $54 \%(266 / 493)$, while the acceptance rate of Five Wishes was 82\% (369/450). (Tables 3 and 4). Unadjusted analyses indicated no significant difference in offering rates between study groups $(\mathrm{OR}=1.14 ; 95 \% \mathrm{CI}, 0.97$ to $1.33 ; P=.11)$. However, the odds of accepting Five Wishes was 3.89 times greater than that of the OKAD (95\% CI 2.88 to $5.24 ; P<.0001)$.

Logistic regression analyses controlling for age, gender, and CCI found no significant difference across study groups for offering $\mathrm{AD}$ forms ( $\mathrm{OR}=$ $0.88 ; 95 \%$ CI, 0.61 to $1.27 ; P=.506)$. However, in a similar model, the acceptance of Five Wishes was favored significantly over OKAD $(\mathrm{OR}=1.52 ; 95 \%$ CI, 1.27 to $1.81 ; P<.0001)$.

Logistic regression analyses that modeled offering of any $\mathrm{AD}$ form as a function of CCI while controlling for patient age and gender indicated 
Figure 2. Age distribution pf participating patients in the study.

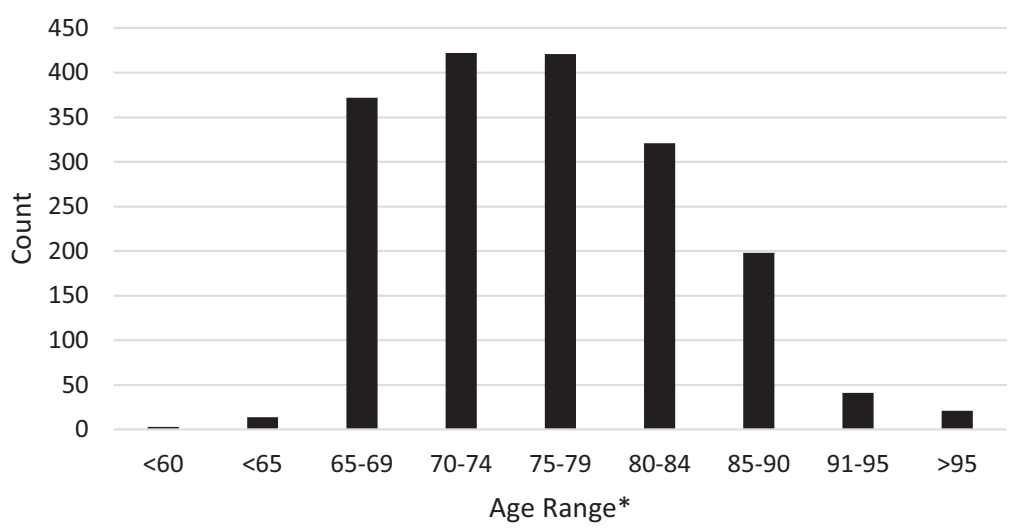

that each unit score increase in CCI was associated with a $78 \%$ increase in the likelihood of offering an $\mathrm{AD}$ form (95\% CI, 1.14 to $2.76 ; P=$ $.04)$. We found a similar effect when modeling $\mathrm{AD}$ form acceptance as the function of CCI $(\mathrm{OR}=1.26 ; 95 \% \mathrm{CI}, 1.01$ to $1.56 ; P=.04)$, indicating that an increase in CCI was associated with a higher likelihood of accepting an $\mathrm{AD}$ form.

After adjusting for the correlation among patients within a practice using GEEs, although the odds of acceptance were higher with Five Wishes, the increase was not statistically significant. Among participants who were offered an $\mathrm{AD}$ form the odds of accepting Five Wishes were 3.26 times the odds of accepting OKAD (OR $=3.26,95 \%$ CI, 0.13 to $80.56, P=.47)$.

\section{Qualitative Outcomes}

Of the weighted list of 100 study patients, 12 agreed to participate in interviews (5, OKAD; 7 , Five Wishes). All clinicians were interviewed (3, Five Wishes; 5, OKAD). Five overarching themes were identified in clinician/patient interviews 1) Capturing Wishes; 2) Reading Level, Language, and Form Design; 3) Family and Cultural Context; 4) Implementation Success/Completing the $\mathrm{AD}$; and 5) Facilitating EOL Discussions. There were 2 additional clinician-specific themes: 1) Care Process Factors; and 2) The Time Factor (see Table 5).

\section{Themes Shared between Patients and Clinicians Capturing Wishes}

Clinicians in the OKAD arm found the form to be generally acceptable with varying opinions about the form's performance, most of which were neutral. In comparison, Five Wishes received more uniformly positive comments from clinicians regarding its ability to represent the wishes of patients.

OKAD patient responses expressed limited enthusiasm with several patients unable to remember the form specifically and thus were not able to comment about it. Patients receiving Five Wishes stated that the form captured their wishes "quite well" or "very well" and that it gave them the flexibility to express their priorities. They also remembered and mentioned specific parts of the forms they liked, such as Wish Number Five (What I Want My Loved Ones to Know).

\section{Reading Level, Language, and Form Design}

OKAD clinician responses in this category were generally tepid with concerns of readability due to the use of medical and legal jargon. As a result, they were worried about whether patients really under-

Table 3. Cumulative Utilization Statistics for the Two Forms: OKAD Versus Five Wishes

\begin{tabular}{lcccccc}
\hline Form & Eligible & Offered & Offered/Eligible, \% & Accepted & Accepted/Offered, \% & Accepted/Eligible, \% \\
\hline OKAD & 1494 & 493 & 33 & 266 & 54 & 18 \\
Five Wishes & 1254 & 450 & 36 & 369 & 82 & 29 \\
\hline
\end{tabular}

OKAD, Oklahoma Advance Directive. 
Table 4. AD Form Utilization Distribution by Practices

\begin{tabular}{|c|c|c|c|c|c|c|c|c|}
\hline Form & Practice & Weeks in Study & Eligible & Offered & $\mathrm{O} / \mathrm{E}$ & Accepted & $\mathrm{A} / \mathrm{O}$ & $\mathrm{A} / \mathrm{E}$ \\
\hline \multirow[t]{3}{*}{ OKAD } & 1 & 17 & 816 & 288 & $35 \%$ & 147 & $51 \%$ & $18 \%$ \\
\hline & $3^{*}$ & 17 & 134 & 68 & $51 \%$ & 39 & $57 \%$ & $29 \%$ \\
\hline & $6^{*}$ & 14 & 544 & 137 & $25 \%$ & 80 & $58 \%$ & $15 \%$ \\
\hline \multirow[t]{3}{*}{ Five Wishes } & $2^{*}$ & 22 & 413 & 163 & $39 \%$ & 93 & $57 \%$ & $23 \%$ \\
\hline & 4 & 15 & 733 & 254 & $35 \%$ & 252 & $99 \%$ & $34 \%$ \\
\hline & 5 & 16 & 108 & 33 & $31 \%$ & 24 & $73 \%$ & $22 \%$ \\
\hline Total & & & 2748 & 943 & $34 \%$ & 635 & $67 \%$ & $23 \%$ \\
\hline
\end{tabular}

*Practices going through electronic health record transition during this study.

A, accepted; AD, Advance Directive; E, eligible; O, offered, OKAD, Oklahoma Advance Directive.

stood what they were signing, particularly in light of known patient literacy limitations. Clinicians were more positive about Five Wishes' readability and design.

Most patients initially stated that the OKAD was "easy to read," but their subsequent responses demonstrated incongruence with this statement. In fact, they expressed considerable difficulty with reading and understanding the OKAD form. This was predominantly related to the form's complicated and legalistic language. Many patients expressed confusion about the statements they were signing and often needed assistance with the form.

In contrast, no Five Wishes patients demonstrated confusion about the purpose of the form's sections. They reported that it used simple language and was easy to follow.

Although Five Wishes was much longer than the OKAD (11 pages vs 4 pages), neither clinicians nor patients complained about the length of the form, even when asked directly.

\section{Family and Cultural Context}

OKAD clinicians reported concerns with patients choosing health care proxies. This is similar to what was found in the Five Wishes in that several patients wanted more than 1 person to be equally responsible for this section. The OKAD does not clearly indicate the need for prioritization, however, whereas the Five Wishes does. Generally, clinicians felt that Five Wishes had cross-cultural acceptance and allowed differences to be discussed respectfully and sensitively. A clinician commented that Five Wishes was easier for patients to read in Spanish than the OKAD and he felt it translated well. Five Wishes clinicians felt that the conversational nature of the form made it easier for patients to discuss in the office and at home.
Patients expressed the desire for more than 1 person to share proxy decision-making responsibilities and the challenge this presents in families. This was expressed in both arms of the study. Patients in the Five Wishes arm volunteered they would discuss the form at home with their families more than the OKAD form.

\section{Implementation Success}

Clinicians in both study arms expressed similar challenges regarding AD implementation success. The OKAD clinicians expressed that the process of this study assisted with the distribution of the forms. The Five Wishes clinicians also expressed this but commented that the form itself was more accessible to patients and better accepted by patients when offered. Both patient groups commented that any clinician conversations about the forms were helpful, although these comments were more frequent in the Five Wishes group. The OKAD seemed more difficult than the Five Wishes for people to complete, based on the clinician observations and the patient statements about the form.

\section{Facilitating EOL Care Discussions}

Several clinicians were already comfortable with the introduction of EOL care conversations and felt that the increased focus on $\mathrm{AD}$ implementation allowed them to explore this topic. One of the clinicians felt that Five Wishes helped his patients understand their personal responsibility to make EOL decisions.

Patients in both arms of the study noted conversations with medical staff/clinicians were helpful, 
Table 5. Representative Quotes from Qualitative Interviews with Patients and Clinicians

\begin{tabular}{|c|c|c|c|}
\hline \multirow[b]{2}{*}{ Theme } & \multirow[b]{2}{*}{ Subtheme } & \multicolumn{2}{|c|}{ Representative Quotes } \\
\hline & & OKAD & Five Wishes \\
\hline \multirow[t]{3}{*}{ Capturing wishes } & Clinicians & $\begin{array}{l}\text { - I tell the patients, 'If it is not clear [the wording } \\
\text { of the form], write it in [ie., patients write in } \\
\text { their wishes on the form].' Then it does fine. } \\
\text { [This is a workaround this clinician devised for } \\
\text { the OKAD]. }\end{array}$ & $\begin{array}{l}\text { - I think it captures their wishes } \\
\text { very well and helps stimulate } \\
\text { questions and other information or } \\
\text { desires they had not thought of in } \\
\text { the past. }\end{array}$ \\
\hline & & $\begin{array}{l}\text { - I think it is good on that. I looked it over. [This } \\
\text { clinician could not identify the details of the } \\
\text { form to explain what he thought made it } \\
\text { adequately designed.] }\end{array}$ & $\begin{array}{l}\text { - It's improved compared to the } \\
\text { state-approved document. }\end{array}$ \\
\hline & & - Useful tool. & $\begin{array}{l}\text { - To me, the way it }[\text { The Five } \\
\text { Wishes form] is developed makes it } \\
\text { a very good document. }\end{array}$ \\
\hline
\end{tabular}

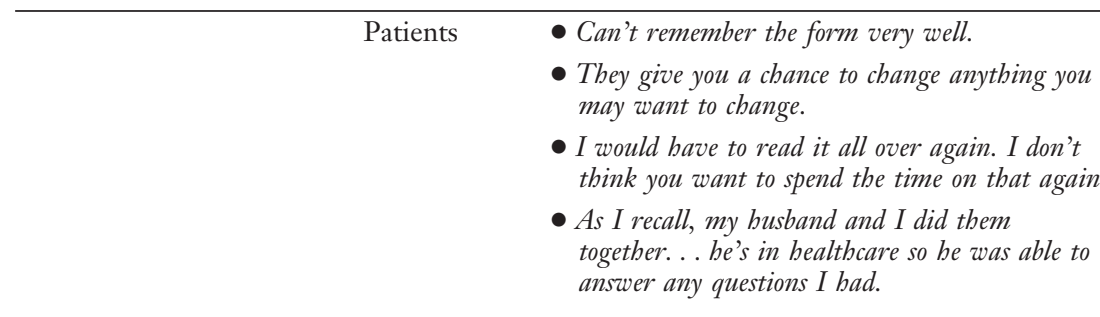

Reading level, language,
and form design
and form design

\section{- About what you would expect}

- It might be a challenge for some people.

- In general, I think it is appropriate, but I probably tend to assume a level of comprehension that my patients may not possess, and I think they are often uncomfortable bringing that up and telling me, even if I ask if they understand it or not.

- I also realized the form itself is very complicated and it's hard to read at a different level

Regarding form design:

- It's $O K$.
- It requires some explanation, but it's OK.

- Typically get zero positive input on the state form [from a clinician in the Five Wishes arm of the study].
- Quite well

- Very well
- I like it. It's worded in a way that people can understand it and what it is.

- They can understand how to word or communicate what they want out of it and it's not so scarysounding in the way that it is worded. The way it is worded it is positive.

- I have given the form out myself to patients who are not enrolled in the study as well.

Regarding form design:

- It's just laid out really simply.

- It's almost like a conversation.

Asked about length:

- I don't know how you can put in there [in the form] everything that has to be covered. So, there is a lot of stuff that goes into it, but it explains everything, so I think if you take that out it makes it to where they can't understand what you're asking of them. You can make it short and they're not going to answer it. 
Table 5. Continued

\begin{tabular}{|c|c|c|c|}
\hline \multirow[b]{2}{*}{ Theme } & \multirow[b]{2}{*}{ Subtheme } & \multicolumn{2}{|c|}{ Representative Quotes } \\
\hline & & OKAD & Five Wishes \\
\hline & Patients & $\begin{array}{l}\text { - Well, with all those extra pages [explanatory } \\
\text { booklet] that they gave me, and I thought 'Ob } \\
\text { my word!'. . it just kept me putting it aside } \\
\text { because I didn't want to mess with it. }\end{array}$ & $\begin{array}{l}\text { - I thought it was very informative, } \\
\text { really, gave me a lot of ideas I } \\
\text { wouldn't think of if I didn't bave } \\
\text { this form. }\end{array}$ \\
\hline & & $\begin{array}{l}\text { - In fact, we had checked some stuff that we } \\
\text { didn't understand until the RN told us, 'now, } \\
\text { do you understand that when you check off that } \\
\text { they use all parts of your body, but if you just } \\
\text { specify the ones that you want done, your body } \\
\text { will only take } 2 \text { days but otherwise it will take } \\
2 \text { weeks.' }\end{array}$ & $\begin{array}{l}\text { - ... If you have seen the regular } \\
\text { one [state form], then you know } \\
\text { what a bunch of jumble mumble }[\text { it } \\
\text { is]!. . . but this one is-I just don't see } \\
\text { bow it could be much simpler. }\end{array}$ \\
\hline & & & - Very easy to understand. \\
\hline & & & - It explains itself very well. \\
\hline & & & $\begin{array}{l}\text { - I bave no qualms with it at all. I } \\
\text { understood it. }\end{array}$ \\
\hline \multirow{5}{*}{$\begin{array}{l}\text { Family and cultural } \\
\text { context }\end{array}$} & Clinicians & - Frequently people want to put more than one & - Health care proxy selection easier. \\
\hline & & name on a hne. & $\begin{array}{l}\text { - Allows discussion of cultural } \\
\text { differences in a respectful and } \\
\text { culturally-sensitive manner. }\end{array}$ \\
\hline & & & - Several people really liked Wish 5. \\
\hline & Patients & $\begin{array}{l}\text { - I had already [completed an AD], once I saw } \\
\text { that Terri Schiavo mess and how they were } \\
\text { recommending it. Plus, my mother died without } \\
\text { one and they had to pull the plug ... and that } \\
\text { was like } 10 \text { years ago. So that is when we } \\
\text { thought, 'No. we need to make sure we have } \\
\text { this.' }\end{array}$ & $\begin{array}{l}\text { - The only problem I had with it is, } \\
\text { I am sitting here looking at it } \\
\text { right now, I had talked to my } \\
\text { daughter it said first 1st choice and } \\
\text { second choice, but my two } \\
\text { daughters felt like they should both } \\
\text { be the person to belp with my care, } \\
\text { not the second choice }\end{array}$ \\
\hline & Patients & $\begin{array}{l}\text { - I must say my son was really wigged out that be } \\
\text { thought he was in charge of deciding whether to } \\
\text { pull the plug or not. My daughter is a } \\
\text { respiratory therapist and so she just told bim to } \\
\text { not worry about it-'You won't be the only one } \\
\text { there. I can make sure it's a hopeless kind of } \\
\text { thing.' [however, daughter lives out of state, so } \\
\text { son is first on HCP form]. }\end{array}$ & \\
\hline \multirow[t]{3}{*}{ Implementation success } & Clinicians & $\begin{array}{l}\text { - I feel like I have a decent number of patients } \\
\text { that have completed it but percentage wise, I } \\
\text { don't know [answer to the question as to bow } \\
\text { successful the clinician thought they were with } \\
\text { implementation]. }\end{array}$ & $\begin{array}{l}\text { - The Five Wishes form is more } \\
\text { accessible [than the state form]. }\end{array}$ \\
\hline & & - Not good. & $\begin{array}{l}\text { - I know of a number of patients } \\
\text { who bave brought the [completed] } \\
\text { form in to me [since the start of } \\
\text { this study]. }\end{array}$ \\
\hline & & & $\begin{array}{l}\text { - [Our lack of success of } \\
\text { implementation had nothing] to do } \\
\text { with the form. It's just } \\
\text { remembering to get that in. The } \\
\text { form itself is fine. }\end{array}$ \\
\hline
\end{tabular}

Continued 
Table 5. Continued

\begin{tabular}{|c|c|c|c|}
\hline \multirow[b]{2}{*}{ Theme } & \multirow[b]{2}{*}{ Subtheme } & \multicolumn{2}{|c|}{ Representative Quotes } \\
\hline & & OKAD & Five Wishes \\
\hline & Patients & $\begin{array}{l}\text { - It's with all of those other pages they gave me } \\
\text { and I thought, 'Ob my word!'... it just kept } \\
\text { me putting it aside because I didn't want to } \\
\text { mess with it. } \\
\text { - I got everything on there. I just got to get it } \\
\text { back to bim [the doctor]. }\end{array}$ & $\begin{array}{l}\text { - I know I should bave already bad } \\
\text { it turned back in. }\end{array}$ \\
\hline \multirow[t]{4}{*}{$\begin{array}{l}\text { Facilitating EOL } \\
\text { discussions }\end{array}$} & Clinicians & $\begin{array}{l}\text { - I tell patients, 'I know it is silly, but it is } \\
\text { important for us to have these } \\
\text { conversations... the state requires that I } \\
\text { do... it's really just protecting your family } \\
\text { when you are no longer able to state your } \\
\text { wishes.' } \\
\text { - I think it has been helpful. }\end{array}$ & $\begin{array}{l}\text { - [this form] helps patients } \\
\text { understand their responsibility (for } \\
\text { the need to make end of life care } \\
\text { decisions): 'Who would speak for } \\
\text { you [if you couldn't speak for } \\
\text { yourself]?' } \\
\text { - Prior to this study I thought I was } \\
\text { doing a pretty good job. During } \\
\text { the study I realized that the form } \\
\text { itself was important. }\end{array}$ \\
\hline & & - I haven't noticed that it has done much for that. & $\begin{array}{l}\text { - The [Five Wishes] form itself does } \\
\text { facilitate the communication part } \\
\text { at bome more so than the others } \\
\text { [other AD forms]. }\end{array}$ \\
\hline & & $\begin{array}{l}\text { - More concrete. Takes the feeling out of it, the } \\
\text { emotional component out of it. It's more } \\
\text { cognitive. You know, 'Check, check, check.' }\end{array}$ & $\begin{array}{l}\text { - [The Five Wishes form] gets you } \\
\text { to think about how you would } \\
\text { want to get care if you were very } \\
\text { sick. }\end{array}$ \\
\hline & Patients & $\begin{array}{l}\text { - Right now, I am healthy. I am not giving it too } \\
\text { much thought of what my end of life will be } \\
\text { like, but if I was closer to death I would } \\
\text { probably be a bit more [interested in this type of } \\
\text { discussion.] }\end{array}$ & $\begin{array}{l}\text { - I don't know if I can tell you how } \\
\text { she [the nurse] explained it to me, } \\
\text { but she did explain it enough. }\end{array}$ \\
\hline
\end{tabular}

AD, Advance Directive; EOL, end of life; HCP, healthcare Proxy; OKAD, Oklahoma Advance Directive; RN, registered nurse.

even though interactions were time limited. Different life events affected patients' perceptions of the need for an $\mathrm{AD}$, such as their current health status, watching loved ones suffer, and EOL court cases (see Table 6).

\section{Clinician-Specific Themes}

\section{Care Process Factors}

General challenges to implementation included no standardized implementation process, forgetting to offer the form, the lack of sustainable reminders in place, the novelty of the $\mathrm{AD}$ process, time pressures, patients forgetting to complete/return forms, staff anxiety about conversation initiation, and patient worry about something being wrong with them for the clinician to ask about ADs. Switching electronic health records added its own barrier, which often superseded any other facilitation mechanism in place. If a clinic switched to a new
EHR, virtually all office efficiency and orientation ground to a halt.

Implementation facilitating factors included systematic planning, effective teamwork, securing buy-in from clinic staff before implementation, and professional experience addressing EOL conversations. PF assistance with bringing attention to new process details was also helpful.

\section{The Time Factor}

Time was a concern raised across all groups and settings. Form introduction generally took less than 5 minutes, but 1 clinician routinely spent between 5 to 20 minutes in these conversations. Most physicians did not mind finding the time for the conversations because they felt it was important. They were also appreciative that the time required for these conversations is now reimbursable. 


\begin{tabular}{ll}
\hline Qualitative Themes for Clinicians & \\
\hline Subtheme & Common barriers to implementation for both forms \\
Time & - Almost all clinicians in both study arms reference the extra time required, ranging from 30 seconds \\
& to 20 minutes, averaging approximately 3 to 5 minutes extra. \\
& - Several didn't mind finding the time because they felt it was important. Reimbursement codes belp. \\
& - Forgetting to offer forms, misunderstandings about bow to address existing/multiple forms, pts \\
Barriers and facilitators & forgetting to complete forms, pts forgetting to return forms, new EHR implementation, location \\
identified & and managing forms in EMR. Facilitators: involvement of nursing staff as part of the \\
& introduction, important to be part of the check-in flow/routine, offer to everyone, script cards for \\
& nursing staff. \\
& Lack of sustainable reminders in place; numerous competing priorities; time pressures; EHR system \\
& change; Facilitators: systematic planning; effective teamwork; securing buy-in from entire clinic \\
& prior to implementation; professional experience with EOL conversations; "Bringing the attention." \\
\hline
\end{tabular}

EHR, electronic health record; EOL, end-of-life.

\section{Discussion}

Our mixed-methods study found that Five Wishes was better accepted by clinicians and patients alike. We identified 3 major rate-limiting factors for $\mathrm{AD}$ implementation: 1) an understandable $\mathrm{AD}$ form that reliably captures patient wishes; 2) an effective process for offering $\mathrm{AD}$ forms in primary care settings; and 3) ensuring that $\mathrm{AD}$ forms are completed and documented in the chart in a timely manner ("closing the loop"). Based on the findings of this study we have found that successful AD implementation will require the systematic application of these factors.

The most important finding of the qualitative analyses was the positive feedback about the usability and utility of Five Wishes. Patient acceptance and initiation of EOL care discussions was also easier with Five Wishes, which may make the closing of the EOL care gaps faster. A lower reading level made the form more understandable. It also helped with addressing needs such as literacy issues, greater patient frailty, chronic conditions, and diverse cultural contexts. The number of personal and social issues addressed and increased free text space were seen as improvements over OKAD. Patients and clinicians repeatedly stated that Five Wishes made it easier to discuss the importance of EOL in a more person-centered manner.

Patients in the Five Wishes group could more readily initiate a discussion about important EOL care choices with doctors and loved ones. Comments from patients about communication with their clinician's office were more enthusiastic in the Five Wishes group. Five Wishes made the conversations easier and more memorable, leading to more positive comments.
Several clinicians discussed the problem of capturing more than 1 health care proxy in a prioritized manner. OKAD is ambiguous about how to document multiple proxies (eg, 1 or more per line) or how to clearly indicate priorities regarding multiple proxies. Five Wishes was better designed and included more specific instructions including space to list the designees' names, addresses, and phone numbers.

One key recommendation of the IOM study is to improve "Professional Education and Development." In our study, several clinicians stated that being in the study improved their skills of reviewing the $\mathrm{AD}$ forms with patients, including clinicians who felt they were already attuned to this before the study. Clinicians also expressed that the study helped them improve their EOL conversations.

Our study indicated that the reliable provision of $\mathrm{AD}$ forms was challenging in all practice sites. In 2016, PerryUndem, a national public opinion communications and research firm, conducted a telephonic survey of 736 physicians who saw people over 65 years (primary care, oncology, pulmonology, and cardiology) regarding ACP and EOL care conversations. ${ }^{18}$ Ninety-nine percent of the participants said ACP conversations were very important for good patient care, yet only $17 \%$ of patients reported talking about EOL issues or ACP with their physicians. ${ }^{19}$ Solberg's practice change model $^{20}$ states that priority of change is a key factor, yet both studies demonstrate that prioritization of this conversation requires more than just desire to make it different. With most guideline implementation efforts, practices need to adopt multipronged, system-level process improvements to provide evidence-based services with high fidelity. 
Identifying practice-level barriers to $\mathrm{AD}$ implementation as well as actions to overcome these barriers (eg, through best practices research) will help clinicians achieve better results. PerryUndem found that clinicians who more frequently discuss ACP issues were more likely to work in a hospital setting, have had formal EOL training, and have formal structures in place in their practices to assess patients' EOL wishes. ${ }^{18}$ Primary care has other major barriers as well; the scope of practice is wide, while time is insufficient. Thus, all solutions must be streamlined and aligned with other competing priorities for success. This requires careful tailoring of new implementations to the environment and needs of end-users, which can be accomplished through practice facilitation. ${ }^{21-22}$ Streamlining is especially important for $\mathrm{AD}$ implementation, since it addresses a highly sensitive and more complex topic, often requiring human touch and deeper personal interaction.

Our results clearly indicate that clinician and patient participants responded more positively when the $\mathrm{AD}$ form was introduced by medical staff and then discussed briefly with the clinician. This structured teamwork approach helped address several fundamental problems, including waiting to see who would bring up the subject first; struggling for the right words to say; and knowing when it is the right time for the conversation.

Initiating discussions about ADs is a multi-faceted challenge that has emotional and personal components. Directly addressing general reluctance to EOL conversation initiation with clinic staff, observing behavior, and providing targeted advice/resources are appropriate strategies to alleviate this problem. Clinic staff engagement in the process of implementing $\mathrm{AD}$ forms and education have been pivotal to identifying and addressing barriers.

The EHR was repeatedly cited as a barrier to documenting the offering of the $\mathrm{AD}$, or the "closing of the loop." In the PerryUndem study 59\% of physicians with access to an EHR where ACPs are easily located were more likely to talk with patients about their ACPs. However, being able to see that there is an ACP in the chart is different from being able to see the contents of the ACP. Of those who could locate the ACP in the EHR, only $31 \%$ could actually see the document contents. These systemic barriers need to be addressed to improve the rate of implementation. Asking physicians to engage in $\mathrm{AD}$ conversations without giving them tools to appropriately document and view the results is counterproductive.

Patients come to clinical visits with their personal notions, fears, literacy limitations, culture, community relations, and family dynamics. These factors may have far-reaching implications including whether they return a completed $\mathrm{AD}$ form to the practice. It is important to recognize and compassionately address these limitations as they arise to improve their comfort with $\mathrm{AD}$ completion.

\section{Limitations}

While we were able to improve the less than $10 \%$ baseline rate of offering $\mathrm{ADs}$ during this study, our overall offering rate was only $34 \%$. A number of challenges need to be addressed for widespread utilization of $\mathrm{AD}$ forms in the broader population. These include time pressure, staff buy-in for the project, discomfort with the subject, fear that patients will think clinicians are foretelling dire diagnoses, etc. These can be addressed through systemic implementation which can ensure: consistent $\mathrm{AD}$ offering patterns, training of clinic staff/clinicians to initiate/participate in meaningful conversations, and provision of visual cues to remind patients and clinical staff to talk about ACP. Our study was limited by a shortened implementation period as well as the low number of study sites which affected our ability to measure $\mathrm{AD}$ completion rates and it widened confidence intervals in our models, particularly the models that account for patient clustering. We anticipate that larger numbers of practice clusters in future studies will address this issue.

Some of our Five Wishes patients and clinicians were exposed to the prevalent OKAD form before the study. However, this slight contamination effect strengthens our findings, since it occurred in the better-performing group.

\section{Conclusion}

Our study underscores the importance of addressing $\mathrm{AD}$ implementation barriers through a multifaceted approach. A comprehensive approach may include the utilization of a well-performing $\mathrm{AD}$ form and the initiation of $\mathrm{AD}$ conversations during routine patient intake process. Implementing ADs through teamwork involving clinicians and staff is pivotal to help formulate consistent and more effective messages across the practice. 
The authors wish to express their appreciation to Aging with Dignity for graciously supplying a portion of the Five Wishes forms used in this study, Dr. Sara Vesely for her assistance in the statistical modeling for the study design, and Dr. Julie Stoner for her statistical assistance with the Generalized Estimating Equation analysis.

To see this article online, please go to: bttp://jabfm.org/content/ 32/2/168.full.

\section{References}

1. Institute of Medicine; Committee on Approaching Death. Dying in America: Improving quality and bonoring individual preferences near the end of life. Washington, DC: National Academies Press, 2015.

2. Benson WF, Aldrich N. Advance Care Planning: Ensuring Your Wishes Are Known and Honored If You Are Unable to Speak for Yourself. CDC Healthy Aging Program [pdf]. 2012. Critical Issues Brief. Available from: https://www.cdc.gov/aging/ pdf/advanced-care-planning-critical-issue-brief.pdf. Accessed August 6, 2018.

3. Wickersham E. Email Survey of OKPRN members regarding percentage of completed Advance Directives on file in office. Internal Data OUHSC; 2015.

4. Fischer S, Min SJ, Cervantes L, Kutner J. Where do you want to spend your last days of life? Low concordance between preferred and actual site of death among hospitalized adults. J Hosp Med 2013;8:178183.

5. Sudore RL, Landefeld CS, Barnes DE, et al. An advance directive redesigned to meet the literacy level of most adults: A randomized trial. Patient Educ Couns 2007;69(1-3):165-195.

6. Office OLR. Adult literacy in Oklahoma. 2015. Available from: https://libraries.ok.gov/literacy/factsstatistics/. Accessed on November 20, 2017.

7. Dignity AW. Five wishes document. 2017. Available from: https://agingwithdignity.org/five-wishes. Accessed on November 20, 2017.

8. Mueller LA, Reid KI, Mueller PS. Readability of state-sponsored advance directive forms in the United States: A cross sectional study. BMC Med Ethics 2010;11:6.

9. Imai KK, G, and Nall C. The essential role of pair matching in cluster-randomized experiments, with application to the Mexican Universal Health Insurance Evaluation. Stat Sci 2009;24:29-53.

10. Charlson ME, Pompei P, Ales KL, MacKenzie CR. A new method of classifying prognostic comorbidity in longitudinal studies: Development and validation. J Chronic Dis 1987;40:373-383.
11. Baskerville NB, Hogg W, Lemelin J. The effect of cluster randomization on sample size in prevention research. J Fam Pract 2001;50:W241-W246.

12. Campbell MJ. Cluster randomized trials in general (family) practice research. Stat Methods Med Res 2000;9:81-94.

13. Harris PA, Taylor R, Thielke R, Payne J, Gonzalez N, Conde JG. Research electronic data capture (REDCap)-A metadata-driven methodology and workflow process for providing translational research informatics support. J Biomed Inform 2009; 42:377-381.

14. Reed JF 3rd. Adjusted chi-square statistics: Application to clustered binary data in primary care. Ann Fam Med 2004;2:201-203.

15. Mancl LA, DeRouen TA. A covariance estimator for GEE with improved small-sample properties. Biometrics 2001;57:126-134.

16. Hsieh HF, Shannon SE. Three approaches to qualitative content analysis. Qual Health Res 2005;15: 1277-1288.

17. PerryUndem Research/Communication. Physicians' views toward advance care planning and end-of-life care conversations: Findings from a national survey among physicians who regularly treat patients 65 and older. April 2016. Available from: https://www. cambiahealthfoundation.org/assets/files/Advance_ Care_Report_F_Embargo.pdf.

18. Palosky C. Public strongly favors end-of-life conversations between doctors and patients, with about eight in 10 saying medicare and other insurers should cover these visits. 2015. Available from: https:// www.kff.org/health-costs/press-release/publicstrongly-favors-end-of-life-conversations-betweendoctors-and-patients-with-about-eight-in-10-sayingmedicare-and-other-insurers-should-cover-thesevisits/. Accessed on June 4, 2018.

19. Solberg LI. Improving medical practice: A conceptual framework. Ann Fam Med 2007;5:251-256.

20. Nagykaldi Z, Mold JW, Aspy CB. Practice facilitators: A review of the literature. Fam Med 2005;37: 581-588.

21. Nagykaldi Z, Mold JW, Robinson A, Niebauer L, Ford A. Practice facilitators and practice-based research networks. J Am Board Fam Med 2006;19: $506-510$.

22. Liddy C, Laferriere D, Baskerville B, Dahrouge S, Knox L, Hogg W. An overview of practice facilitation programs in Canada: Current perspectives and future directions. Healthc Policy 2013;8: $58-67$. 